Behavioral meaningful opioidergic stimulation activates kappa receptor gene expression

E. Teodorov, M.F.R. Ferrari, D.R. Fior-Chadi, R. Camarini and L.F. Felício

The Brazilian Journal of Medical and Biological Research is partially financed by

\section{Q}

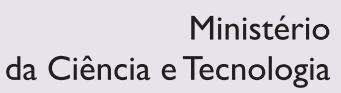

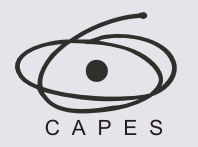

Ministério da Educação
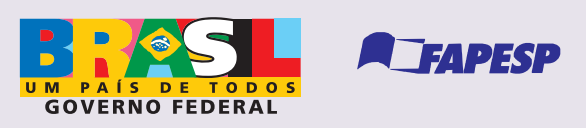

Institutional Sponsors

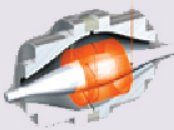

Ф SHIMADZU UNICAMP
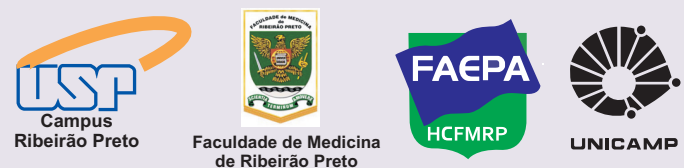


\title{
Behavioral meaningful opioidergic stimulation activates kappa receptor gene expression
}

\author{
E. Teodorov ${ }^{1}$, M.F.R. Ferrari² ${ }^{2}$ D.R. Fior-Chadi ${ }^{3}$, R. Camarini ${ }^{4}$ and L.F. Felício ${ }^{5}$ \\ ${ }^{1}$ Centro de Matemática, Computação e Cognição, Universidade Federal do ABC, São Paulo, SP, Brasil \\ 2Departamento de Genética e Biologia Evolutiva, Instituto de Biociências, \\ Universidade de São Paulo, São Paulo, SP, Brasil \\ ${ }^{3}$ Departamento de Fisiologia, Instituto de Biociências, Universidade de São Paulo, São Paulo, SP, Brasil \\ ${ }^{4}$ Departamento de Farmacologia, Instituto de Ciências Biomédicas, \\ Universidade de São Paulo, São Paulo, SP, Brasil \\ ${ }^{5}$ Departamento de Patologia, Faculdade de Medicina Veterinária e Zootecnia, \\ Universidade de São Paulo, São Paulo, SP, Brasil
}

\begin{abstract}
The periaqueductal gray (PAG) has been reported to be a location for opioid regulation of pain and a potential site for behavioral selection in females. Opioid-mediated behavioral and physiological responses differ according to the activity of opioid receptor subtypes. The present study investigated the effects of the peripheral injection of the kappa-opioid receptor agonist U69593 into the dorsal subcutaneous region of animals on maternal behavior and on Oprk1 gene activity in the PAG of female rats. Female Wistar rats weighing $200-250 \mathrm{~g}$ at the beginning of the study were randomly divided into 2 groups for maternal behavior and gene expression experiments. On day 5, pups were removed at 7:00 am and placed in another home cage that was distant from their mother. Thirty minutes after removing the pups, the dams were treated with $U 69593(0.15 \mathrm{mg} / \mathrm{kg}, \mathrm{sc})$ or $0.9 \% \mathrm{saline}$ (up to $1 \mathrm{~mL} / \mathrm{kg}$ ) and after $30 \mathrm{~min}$ were evaluated in the maternal behavior test. Latencies in seconds for pup retrieval, grouping, crouching, and full maternal behavior were scored. The results showed that U69593 administration inhibited maternal behavior $(P<0.05)$ because a lower percentage of $U 69593$ group dams showed retrieval of first pup, retrieving all pups, grouping, crouching and displaying full maternal behavior compared to the saline group. Opioid gene expression was evaluated using real-time reverse-transcription polymerase chain reaction (RT-PCR). A single injection of U69593 increased Oprk1 PAG expression in both virgin $(P<0.05)$ and lactating female rats $(P<0.01)$, with no significant effect on Oprm1 or Oprd1 gene activity. Thus, the expression of kappa-opioid receptors in the PAG may be modulated by single opioid receptor stimulation and behavioral meaningful opioidergic transmission in the adult female might occur simultaneously to specific changes in gene expression of kappa-opioid receptor subtype. This is yet another alert for the complex role of the opioid system in female reproduction.
\end{abstract}

Key words: Real-time reverse-transcription polymerase chain reaction; Opioid receptor; Gene expression; Opioid sensitivity; Kappa opioid receptor

\section{Introduction}

Opioidergic stimuli modulate various sensory systems with behavioral consequences for both male and female mammals (1-9). The periaqueductal gray (PAG) is likely to influence a number of brainstem sites that are critically involved in controlling both somatomotor (e.g., mating) and autonomic (e.g., thermoregulation) responses, as well as hypothalamic regions related to the control of generalized arousal and sensorimotor integration $(10,11)$. The PAG is also known to play important roles in the modulation of nociceptive sensory transmission, regulation of the car- diovascular system (12), vocalization (13), and expression of a variety of behaviors, including defensive (14), sexual (15), maternal (16-18), and feeding behaviors $(15,19,20)$. The PAG occupies a pivotal position in the central nervous system that influences the selection of adaptive behavioral responses. This region receives both limbic information and a vast array of inputs from prefrontal cortical areas $(21,22)$. Previous studies from our laboratory have suggested an integrative role of opioidergic transmission in the PAG in influencing behavioral selection during lactation $(6,23-25)$. 
The role played by the PAG in maternal behavior may be dependent on adequate local expression of opioid-related genes.

Opioid receptors have been the focus of intense molecular, physiological, and pharmacological research. The PAG has a high density of opioid receptors and activation of these metabotropic, G-protein-coupled receptors modulates various aspects of reproductive behavior in females. There are three types of opioid receptors: mu, delta, and kappa (26). Multiple reproductive experiences influence both gene activity and opioid receptor expression in the PAG. A preliminary study suggested that opioidergic stimulation modulates opioid gene expression in the female PAG $(27,28)$.

Our group has shown that the morphine-induced inhibition of maternal behavior is plastic and adaptive and that opioidergic transmission in the rostral PAG plays a role in this process. In addition, it has been demonstrated that both repeated treatment with morphine and reproductive experience have effects on the expression of opioid receptors. The present study further extends this line of research by investigating the hypothesis that one stimulation would modify the activity of a specific receptor gene. Although the major target of morphine and naloxone is Oprm1, the acute inhibition of maternal behavior induced by kappa receptor stimulation needs more investigation. Because kappa stimulation is behaviorally meaningful, this study was designed to specifically investigate the dynamics of kappa on the PAG. In order to test for indirect or nonspecific effects, the kappa activity of Oprm1 and Oprd1 was also measured.

The present study investigated the effects of U69593, a kappa-opioid receptor agonist, on mu-, kappa-, and deltaopioid receptor Oprm1, Oprk1, and Oprd1 gene activity in the PAG of both lactating and virgin female rats. This was performed by evaluating opioid gene expression using real-time reverse-transcription polymerase chain reaction (RT-PCR).

The aim of the present study was to determine whether a single kappa opioidergic stimulation using the kappa agonist U69593 can promote immediate changes in the activity and expression of the kappa-opioid receptor gene in the PAG of female animals. In order to test for indirect effects of such kappa stimulation on other opioid receptor genes, the activity of mu and delta receptor genes was also measured. Both virgin and lactating rats were tested to determine whether the physiological state influences the response to this agonist.

\section{Material and Methods}

\section{Animals and housing}

Female Wistar rats weighing 200-250 g at the beginning of the study were obtained from Faculdade de Medicina Veterinária, Universidade de São Paulo. The animals were housed in polypropylene cages (32 x $40 \times 18 \mathrm{~cm}$ ) with 3 animals per cage, under conditions of controlled temperature $\left(22 \pm 2^{\circ} \mathrm{C}\right)$, a $12 / 12-\mathrm{h}$ light/dark cycle (lights on at 6:00 am), and free access to food and water during the experimental procedure. All animal procedures were in accordance with the guidelines of the Committee on the Care and Use of Laboratory Animal Resources, National Research Council, USA. We attempted to minimize the number of rats used, and every effort was made to ensure that no rat suffered unnecessarily.

For mating, 2 female rats were placed overnight with 1 sexually experienced male rat. The day on which sperm was observed in the vaginal lavage was designated day 1 of pregnancy. Pregnant rats were housed 2 per cage until day 18 of pregnancy and then individually until the end of the experiments. At parturition, all pups were examined externally, sexed, and weighed, with 8 pups (4 males and 4 females) left with each dam until the maternal behavior test (experiment 1) and gene expression studies (experiment 2).

\section{Maternal tasks}

On day 5 of lactation, pups were removed at 7:00 am and placed in another home cage that was distant from their mother. Thirty minutes after removing the pups, the dams were acutely challenged with U69593 ([5- $, 7-\alpha, 8-\beta]-$ [+]-N-methyl- $N$ - $\{7-(1-$ pyrrolidinyl)-1-oxaspiro[4.5]dec-8-yl\} benzeneacetamide; Sigma Aldrich, USA, $0.15 \mathrm{mg} / \mathrm{kg}, \mathrm{sc}$ ) or saline. Thirty minutes after the injections were given to the dams, all pups were placed back with their mothers, and maternal behavior testing began. Latencies in seconds for pup sniffing, retrieval, grouping, crouching, and full maternal behavior were scored $(2,3)$. Animals were scored as fully maternal if they retrieved all 8 pups to the nest and displayed nursing behavior with their back arched over the pups for 3 consecutive minutes. If animals were not fully maternal after 30 min of continuous observation, they were checked every $15 \mathrm{~min}$ up to $60 \mathrm{~min}$ and then hourly until full maternal behavior was observed. Events observed after the first 30 min of continuous observation were recorded at the time of first observation (e.g., if full maternal behavior was first observed at $60 \mathrm{~min}$, the full maternal behavior latency was scored as $60 \mathrm{~min}$, or $3600 \mathrm{~s}$ ). The same criterion was used for all other responses. For all behavioral tests, the observers were blind to the treatment of the test subjects.

\section{Opioid-selective agonist treatment}

Sixty virgin and lactating rats were randomly divided into two (experiment 1) and four (experiment 2) groups of 10 animals each. They were treated with U69593 (0.15 mg/kg), saline, or no treatment (i.e., no experimental procedures were conducted on these animals, which were defined as blank). Brains were collected on day 5 of lactation. After 1 $h$, the animals were decapitated for PAG dissection using a blade dissecting approximately $2 \mathrm{~cm}^{2}$ around the coordinate anteroposterior: 6.0; dorsoventral: 4.3; mediolateral: 0.6 
coordinates (29). In both experiment, because the results for the saline and no treatment (blank) groups were similar $(P>0.5)$, they are presented as a single group $(N=10)$.

\section{RNA extraction, cDNA construction, and real-time RT-PCR quantification of opioid gene expression}

Total RNA was extracted from each tissue sample using TRIZOL reagent (Invitrogen Life Technologies, USA). Thus, immediately after euthanasia by decapitation, the PAG (approximately $40 \mathrm{mg}$, removed with a scalpel) was suspended in $1 \mathrm{~mL}$ ice-cold TRIZOL, and total RNA was extracted according to manufacturer instructions. The final RNA pellets were resuspended in $50 \mu \mathrm{L}$ diethyl-pyrocarbonatetreated water. The total RNA concentrations were measured spectrophotometrically at $260 \mathrm{~nm}$, and the integrity of RNA samples was analyzed on $1.5 \%$ agarose gel (Sigma, USA) containing ethidium bromide $(0.5 \mu \mathrm{g} / \mathrm{mL})$. Total RNA was then treated with DNase I before further processing and stored at $-80^{\circ} \mathrm{C}$

Oligo DT primers $(1 \mu \mathrm{L})$ and dNTPs $(1 \mu \mathrm{L})$ were added to the total RNA sample $(5 \mu \mathrm{g})$ and incubated at $65^{\circ} \mathrm{C}$ for $5 \mathrm{~min}$; $5 \mathrm{X}$ buffer $(4 \mu \mathrm{L}$; Superscript II RNase H-reverse transcriptase), DTT ( $1 \mathrm{M}, 2 \mu \mathrm{L})$, and RNaseOUT $(1 \mu \mathrm{L})$ were then added, and the mixture was incubated at $42^{\circ} \mathrm{C}$ for $2 \mathrm{~min}$. Superscript II $(1 \mu \mathrm{L})$ was added and the mixture was incubated at $42^{\circ} \mathrm{C}$ for $50 \mathrm{~min}$. An additional incubation was performed at $70^{\circ} \mathrm{C}$ for $15 \mathrm{~min}$. One microliter RNaseH was added for the removal of remaining RNA and the mixture was incubated at $37^{\circ} \mathrm{C}$ for $20 \mathrm{~min}$. All reagents were purchased from Invitrogen Life Technologies.

Real-time RT-PCR was performed using an ABI Prism 7000 Sequence Detection System (Applied Biosystems, USA) with TaqMan Universal Master Mix (part No. 4304437; Applied Biosystems). PCR primers (Applied Biosystems) and the TaqMan probes for Oprm1, Oprd1, Oprk1, and $18 S$ quantification were selected using the Primer Express software (Applied Biosystems), verified by a BLAST search of GenBank, and labeled Rn00565144_m1 for Oprm1, Rn00567737_m1 for Oprk1, RN00561699_m1 for Oprd1, and $4319413 \mathrm{E}$ for $18 \mathrm{~S}$, which was used as a housekeeping control. The primers were chosen to amplify a 65-bp fragment. The internal TaqMan probe (FAM-3'-TCTGGGCA CCTCTCTTT-5'-NFQ) was designed following the general rules outlined by the manufacturer and carried a 5 '-reporter dye [6-carboxy fluorescein (FAM)] and a 3'-non-fluorescent quencher dye (NFQ). The primers and probes were used with $100 \%$ efficiency at final concentrations of 0.9 and 0.25 $\mu \mathrm{M}$, respectively.

The thermal cycling conditions for cDNA quantification assays were established according to ABI Prism 7000 Sequence Detection System parameters. Relative gene expression data were analyzed by the $2^{-\Delta \Delta C T}$ method (30).

\section{Statistical analysis}

Behavioral data were analyzed by comparing the means using the Student $t$-test. The percents of animals showing each behavior during the 30-min test were compared by the Fisher test. Mean gene expression data were compared by the Student $t$-test. Values of $\mathrm{P}<0.05$ were considered to be statistically significant.

\section{Results}

\section{Experiment 1}

The $0.15 \mathrm{mg} / \mathrm{kg}$ dose of $\mathrm{U} 69593$ induced no sedation. Comparison of the saline and $\mathrm{U} 69593$ groups revealed that a lower percentage of U69593 group dams showed retrieval of first pup, and retrieving all pups, grouping, crouching and displaying full maternal behavior. Importantly, latencies to sniff the pups did not differ among groups (Table 1). Animals in the U69593 group continued digging in the wood chips and building nests instead of retrieving pups, resulting in longer latencies to retrieve the pups. Such disruptive effects were not observed in the saline group.

\section{Experiment 2}

Acute U69593 treatment significantly increased Oprk1 expression in virgin female rats $(P<0.05)$. This treatment did not induce alterations in Oprd1 or Oprm1 gene expression in the PAG of virgin female rats (Figure 1). In lactating female rats, U69593 treatment increased only Oprk1 expression $(P<0.01)$. No other significant differences were found in opioid receptor gene expression in lactating rats treated with this drug (Figure 1) in the PAG.

\section{Discussion}

The PAG belongs to a primary anatomical pathway me-

Table 1. Effects of treatment with a selective agonist kappa-opioid receptor (U69593) on maternal behavior on day 5 of lactation.

\begin{tabular}{lcccccc}
\hline Groups & $\begin{array}{c}\text { Latency to sniff } \\
\text { the 1st pup (s) }\end{array}$ & $\begin{array}{c}\text { Retrieving 1st } \\
\text { pup }\end{array}$ & $\begin{array}{c}\text { Retrieving all } \\
\text { pups }\end{array}$ & $\begin{array}{c}\text { Grouping } \\
\text { Crouching }\end{array}$ & $\begin{array}{c}\text { Full maternal } \\
\text { behavior }\end{array}$ \\
\hline Saline & $10 \pm 2.8$ & 100 & 100 & 100 & 100 & 100 \\
U69593 $(0.15 \mathrm{mg} / \mathrm{kg})$ & $12 \pm 3.4$ & $50^{*}$ & $0^{*}$ & $0^{*}$ & $0^{*}$ & $0^{*}$ \\
\hline
\end{tabular}

Data are reported as percentage of animals observed showing the listed behaviors during the first 30 min. Latency to sniff the first pup is reported in seconds (s). ${ }^{*} \mathrm{P}<0.05$ compared to the saline group (Fisher test). 

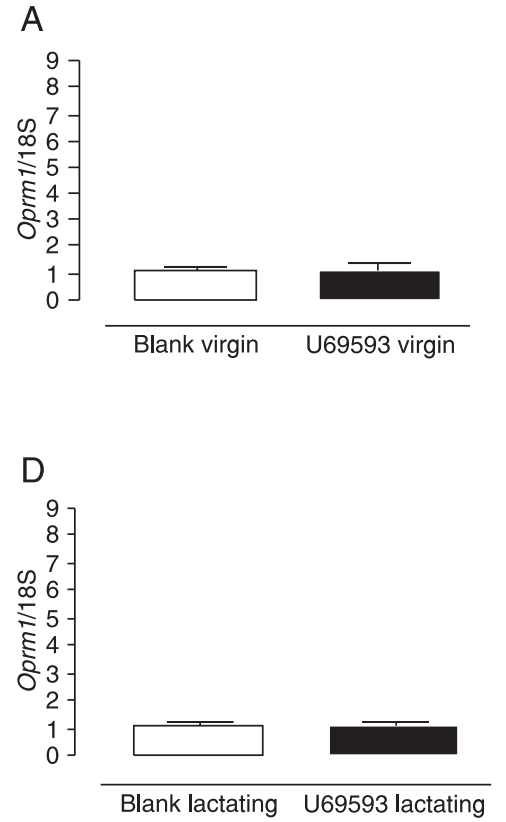

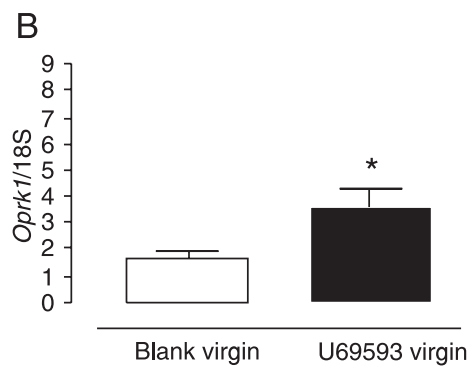

$\mathrm{E}$

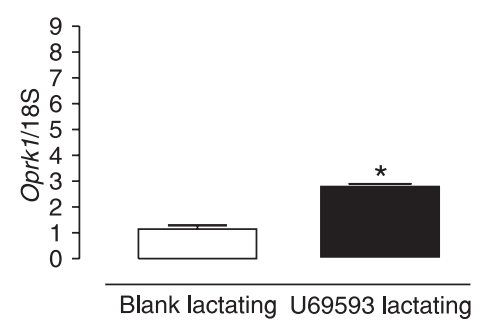

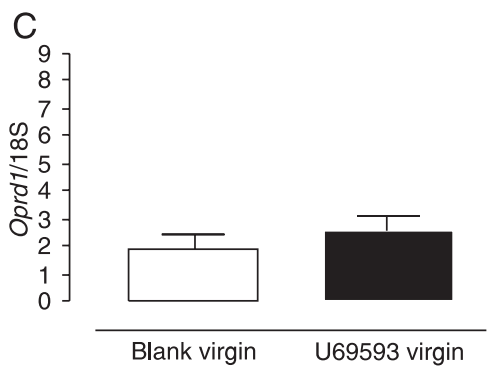

$\mathrm{F}$

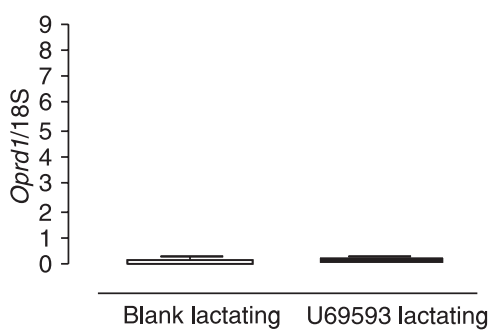

Figure 1. Real-time RT-PCR of $5 \mu \mathrm{g}$ total RNA extracted from the periaqueductal gray of adult virgin $(A, B, C)$ and lactating female rats $(D, E, F)$ in relation to expression of Oprm1, Oprk1 and Oprd1. Data are reported as means $\pm \mathrm{SEM}$. ${ }^{*} \mathrm{P}<0.05$ compared to the blank group (ANOVA).

diating opioid-based analgesia. Morphine administration produces greater antinociception in males than females (31). In reproductive females, physiological activation of one or more PAG opioid receptors interferes with nursing and other aspects of maternal behavior, such as pup retrieval and pup grooming. The physiological role of female PAG opioid receptors, particularly the kappa receptor, has not been well established. The ventrolateral PAG column of the caudal part might be involved in the expression of kyphosis toward pups, which is the arched-back posture that facilitates nursing (17). Maternal aggression and survival strategies involving stressful situations have also been reported to be influenced by opioid receptors $(16,17,32)$. A previous study reported that stimulation of kappa-opioid receptors using different doses of U69593 interferes with maternal behavior (8). Behavioral data reported in the present study show that peripheral injection of $0.15 \mathrm{mg} / \mathrm{kg}$ of the kappa agonist inhibits maternal behavior in lactating rats. On the other hand, other investigators administered a kappa 1 agonist (U69596, $0.1 \mathrm{mg} / \mathrm{kg}$ ) and found no effect on maternal behavior in lactating rats. The larger dose used in the present study may be responsible for this difference. Alternatively, since another drug was used, kinetic differences may have played a role (33).

A previous study from our laboratory has reported the presence of kappa receptor protein in the PAG of both virgin and lactating rats (8). The present study investigated the expression of Oprm1, Oprk1, and Oprd1 in the PAG of female rats by evaluating the gene expression of mu-, kappa-, and delta-opioid receptors in the PAG of animals treated with an acute injection of U69593. The present data suggest that agonist-induced changes in gene expression are similar in both lactating and virgin animals. Treatment with a single peripheral injection of the kappa-opioid agonist U69593 significantly increased kappa receptor gene expression in both lactating and virgin rats. No significant changes were observed for mu or delta receptor genes after this drug challenge. Consistent with its binding affinity for kappa receptors, this action of U69593 on Oprk1 gene activity suggests a specificity of U69593 for actions on the gene encoding the kappa receptor. In the present study, the behavioral effects of acute kappa opioidergic stimulation in lactating rats were confirmed. In addition, the present data add knowledge to this scenario by demonstrating a specific effect of a kappa agonist on a site that has been functionally implicated in behavioral selection during lactation. Acute stimulation increased Oprk1 gene activity in both virgin and lactating animals. This may indicate a lack of endocrine modulation of this response. Thus, a specific immediate and likely compensatory gene response to kappa receptor stimulation is described in animals acutely exposed to a low dose of U69593. Such response may play a role in plastic mechanisms, resulting in different responses to similar pharmacological challenges. This hypothesis is to be tested in future studies.

The present study shows that by stimulating a kappaopioid receptor both inhibition of maternal behavior and enhancement of Oprk1 are achieved. Although more stud- 
ies are necessary to elucidate the functional relationship between these effects, a specific role for the kappa receptor in the context of reproductive behavior now seems feasible. This is yet another alert for the complex role of the opioid system in female reproduction.

\section{References}

1. Mann PE, Felicio LF, Bridges RS. Investigation into the role of cholecystokinin (CCK) in the induction and maintenance of maternal behavior in rats. Horm Behav 1995; 29: 392406.

2. Miranda-Paiva CM, Felicio LF. Differential role of cholecystokinin receptor subtypes in opioid modulation of ongoing maternal behavior. Pharmacol Biochem Behav 1999; 64: 165-169.

3. Miranda-Paiva CM, Nasello AG, Yin AJ, Felicio LF. Morphine pretreatment increases opioid inhibitory effects on maternal behavior. Brain Res Bull 2001; 55: 501-505.

4. Miranda-Paiva CM, Ribeiro-Barbosa ER, Canteras NS, Felicio LF. A role for the periaqueductal grey in opioidergic inhibition of maternal behaviour. Eur J Neurosci 2003; 18: 667-674.

5. Patti CL, Frussa-Filho R, Silva RH, Carvalho RC, Kameda $\mathrm{SR}$, Takatsu-Coleman AL, et al. Behavioral characterization of morphine effects on motor activity in mice. Pharmacol Biochem Behav 2005; 81: 923-927.

6. Patti CL, Kameda SR, Carvalho RC, Takatsu-Coleman AL, Lopez GB, Niigaki ST, et al. Effects of morphine on the plusmaze discriminative avoidance task: role of state-dependent learning. Psychopharmacology 2006; 184: 1-12.

7. Yim AJ, Miranda-Paiva CM, Florio JC, Oliveira CA, Nasello AG, Felicio LF. A comparative study of morphine treatment regimen prior to mating and during late pregnancy. Brain Res Bull 2006; 68: 384-391.

8. Teodorov E, Tomita AT, Banon GP, Gil IG, Bernardi MM, Felicio LF. Behavioral effects of acute stimulation of kappaopioid receptors during lactation. Pharmacol Biochem Behav 2008; 90: 534-539.

9. Cruz AM, Maiorka PC, Canteras NS, Sukikara MH, Felicio LF. Morphine treatment during pregnancy modulates behavioral selection in lactating rats. Physiol Behav 2010; 101: 40-44.

10. Cameron AA, Khan IA, Westlund KN, Cliffer KD, Willis WD. The efferent projections of the periaqueductal gray in the rat: a Phaseolus vulgaris-leucoagglutinin study. I. Ascending projections. J Comp Neurol 1995; 351: 568-584.

11. Cameron AA, Khan IA, Westlund KN, Willis WD. The efferent projections of the periaqueductal gray in the rat: a Phaseolus vulgaris-leucoagglutinin study. II. Descending projections. $J$ Comp Neurol 1995; 351: 585-601.

12. Bandler R, Shipley MT. Columnar organization in the midbrain periaqueductal gray: modules for emotional expression? Trends Neurosci 1994; 17: 379-389.

13. Jurgens $U$. The role of the periaqueductal grey in vocal behaviour. Behav Brain Res 1994; 62: 107-117.

14. Keay KA, Bandler R. Parallel circuits mediating distinct emotional coping reactions to different types of stress. Neurosci Biobehav Rev 2001; 25: 669-678.

\section{Acknowledgments}

Research supported by FAPESP (\#2010/50415-4) and CNPq grants to L.F. Felício (\#478765/04-05) and E. Teodorov (\#2004/54696-0).

15. Sakuma Y, Pfaff DW. Facilitation of female reproductive behavior from mesencephalic central gray in the rat. $A m \mathrm{~J}$ Physiol 1979; 237: R278-R284.

16. Lonstein JS, Stern JM. Role of the midbrain periaqueductal gray in maternal nurturance and aggression: c-fos and electrolytic lesion studies in lactating rats. J Neurosci 1997; 17 : 3364-3378.

17. Lonstein JS, Stern JM. Site and behavioral specificity of periaqueductal gray lesions on postpartum sexual, maternal, and aggressive behaviors in rats. Brain Res 1998; 804: 2135.

18. Moura LM, Canteras NS, Sukikara MH, Felicio LF. Morphine infusions into the rostrolateral periaqueductal gray affect maternal behaviors. Braz J Med Biol Res 2010; 43: 899-905.

19. Carrive $P$. The periaqueductal gray and defensive behavior: functional representation and neuronal organization. Behav Brain Res 1993; 58: 27-47.

20. Van Erp AM, Kruk MR, Meelis W, Veening JG. Periaqueductal gray lesions do not affect grooming, induced electrically in the hypothalamic paraventricular area in the rat. Behav Brain Res 1993; 59: 95-101.

21. Floyd NS, Price JL, Ferry AT, Keay KA, Bandler R. Orbitomedial prefrontal cortical projections to distinct longitudinal columns of the periaqueductal gray in the rat. J Comp Neurol 2000; 422: 556-578.

22. Mota-Ortiz SR, Sukikara MH, Felicio LF, Canteras NS. Afferent connections to the rostrolateral part of the periaqueductal gray: a critical region influencing the motivation drive to hunt and forage. Neural Plast 2009; 2009: 612698.

23. Sukikara MH, Mota-Ortiz SR, Baldo MV, Felicio LF, Canteras NS. A role for the periaqueductal gray in switching adaptive behavioral responses. J Neurosci 2006; 26: 2583-2589.

24. Sukikara MH, Platero MD, Canteras NS, Felicio LF. Opiate regulation of behavioral selection during lactation. Pharmacol Biochem Behav 2007; 87: 315-320.

25. Sukikara MH, Mota-Ortiz SR, Baldo MV, Felicio LF, Canteras NS. The periaqueductal gray and its potential role in maternal behavior inhibition in response to predatory threats. Behav Brain Res 2010; 209: 226-233.

26. Mansour A, Fox CA, Akil H, Watson SJ. Opioid-receptor mRNA expression in the rat CNS: anatomical and functional implications. Trends Neurosci 1995; 18: 22-29.

27. Teodorov E, Modena CC, Sukikara MH, Felicio LF. Preliminary study of the effects of morphine treatment on opioid receptor gene expression in brain structures of the female rat. Neuroscience 2006; 141: 1225-1231.

28. Teodorov E, Bernardi MM, Ferrari MF, Fior-Chadi DR, Felicio LF. Plasticity of opioid receptors in the female periaqueductal gray: multiparity-induced increase in the activity of genes encoding for mu and kappa receptors and a post-translational decrease in delta receptor expression. J Mol Neurosci 2011; 
43: $175-181$.

29. Paxinos G, Watson C. The rat brain: in stereotaxic coordinates. Amsterdam: Elsevier; 2009.

30. Livak KJ, Schmittgen TD. Analysis of relative gene expression data using real-time quantitative PCR and the 2(-Delta Delta C(T)) Method. Methods 2001; 25: 402-408.

31. Loyd DR, Murphy AZ. The role of the periaqueductal gray in the modulation of pain in males and females: are the anatomy and physiology really that different? Neural Plast
2009; 2009: 462879.

32. Pavesi E, Enck MC, De Toledo CA, Terenzi MG. Disruption of maternal behaviour by acute conspecific interaction induces selective activation of the lateral periaqueductal grey. Eur $J$ Neurosci 2007; 26: 2055-2065.

33. Mann PE, Kinsley CH, Bridges RS. Opioid receptor subtype involvement in maternal behavior in lactating rats. Neuroendocrinology 1991; 53: 487-492. 